\title{
O CONCEITO DE CORPOS REGULARES EM ALGUNS LIVROS DIDÁTICOS E SUA RELAÇÃO COM O TRATADO DE DIVINA PROPORTIONE (1509)
}

\section{THE CONCEPT OF REGULAR BODIES IN SOME TEXTBOOKS AND THEIR RELATION WITH THE TREATISE DE DIVINA PROPORTIONE (1509)}

\author{
Alison Sousa da Silva ${ }^{1}$ \\ Instituto Federal de Educação, Ciência e Tecnologia do Ceará - IFCE
}

\begin{abstract}
Resumo
No ensino de geometria espacial, tanto na educação básica quanto no ensino superior, os corpos regulares, também conhecidos como poliedros regulares, compõem um conteúdo que faz parte da grade curricular formativa desses níveis. No que se refere à sua definição, o vigésimo quinto capítulo do tratado De Divina Proportione, escrito pelo frade italiano Luca Pacioli (1447-1517) e publicado em 1509, apresenta elementos pouco usuais no conceito de corpos regulares, a saber: o emprego dos ângulos superficiais e ângulos sólidos; cujas definições são advindas da obra de Euclides, Os Elementos. Nesses parâmetros, o presente estudo tem por objetivo conhecer como está proposta a definição de poliedros regulares em alguns livros didáticos aprovados no Plano Nacional do Livro Didático (PNLD) para o triênio 2018-2020, articulando com os conceitos propostos no tratado De Divina Proportione. Para isso, foi utilizada uma metodologia qualitativa de cunho bibliográfico e documental, tendo como principal critério, a definição de corpos regulares expostas nos livros didáticos escolhidos, para que, posteriormente, sejam estabelecidas relações conceituais envolvendo a obra estudada. Com a realização desse estudo, percebe-se que os livros didáticos indicados se utilizam de escassas informações históricas referentes à geometria espacial, em particular sobre o conceito de corpos regulares, as quais, na sua maioria, se resumem a dados biográficos sobre certos matemáticos. Na intenção de colaborar na redução dessa ausência, se fazem necessários estudos que possibilitem estreitar as relações entre a história e o ensino de matemática, contribuindo na formação de professores de matemática e, consequentemente, de seus alunos.
\end{abstract}

Palavras-chave: Poliedros regulares; Livro didático; Luca Pacioli; De Divina Proportione; História da matemática.

\begin{abstract}
In teaching spatial geometry, both in basic education and in higher education, the regular bodies, also known as regular polyhedra, be part of content that is part of the formative curriculum of these levels. Regarding its definition, the twenty-fifth chapter of the treatise De Divina Proportione, written by the Italian friar Luca Pacioli (1447-1517) and published in 1509, presents unusual elements in the concept of regular bodies, namely: the use of surface angles and solid angles; whose definitions come from the Euclid's work, The Elements. In these parameters, the present study aims to understand how the definition of regular polyhedra is proposed in some textbooks approved in the National Textbook Plan for the triennium 2018-2020, articulating with the concepts proposed in
\end{abstract}

1 alisonsilva1803@gmail.com

Número Especial - IV Seminário Cearense de História da Matemática

Boletim Cearense de Educação e História da Matemática - Volume 07, Número 20, 190 - 201 (2020)

DOI: 10.30938/bocehm.v7i20.2968 
the treatise De Divina Proportione. For this, a qualitative methodology of bibliographic and documentary nature was used, having as main criterion, the definition of regular bodies exposed in the chosen textbooks, so that, posteriorly, conceptual relationships are established involving the work studied. With this study, it is noticed that the indicated textbooks use little historical information regarding spatial geometry, in particular about the concept of regular bodies, which, mostly, it summarizes to biographical data about certain mathematicians. With the intention of collaborating in reducing this absence, studies are needed to make it possible to strengthen the relationship between history and the mathematics teaching, contributing to the training of mathematics teachers and, consequently, of your students.

Keywords: Regular polyhedra; Textbook; Luca Pacioli; De Divina Proportione; History of mathematics.

\title{
Introdução
}

Tópicos de Geometria Espacial compõem um conteúdo abordado no tanto na educação básica quanto no Ensino Superior em diversas formas: através de conceitos, de propriedades, ou ainda, de situações presentes no cotidiano dos alunos. Tal afirmação se justifica perante o apresentado nos documentos oficiais que regulamentam ambos os níveis da educação.

Em uma visão geral, os Parâmetros Curriculares Nacionais (PCN) citam que:

\begin{abstract}
[...] a Geometria tem tido pouco destaque nas aulas de Matemática e, muitas vezes, confunde-se seu ensino com o das medidas. Em que pese seu abandono, ela desempenha um papel fundamental no currículo, na medida em que possibilita ao aluno desenvolver um tipo de pensamento particular para compreender, descrever e representar, de forma organizada, o mundo em que vive (BRASIL, 1998, p. 122).
\end{abstract}

Nesses termos, mesmo a Geometria sendo um dos eixos estruturadores da disciplina de Matemática, se reconhece certo abandono nos currículos, mesmo perante sua importância no processo formativo dos alunos da educação básica.

Com a homologação da Base Nacional Comum Curricular, entende-se que ensino de Geometria não deve se limitar ao ensino através da matemática pura, mas deve ter significado para o aluno, onde este possa relacionar o que aprende na escola com o seu cotidiano, pois:

a Geometria não pode ficar reduzida a mera aplicação de fórmulas de cálculo de área e de volume nem a aplicações numéricas imediatas de teoremas sobre relações de proporcionalidade em situações relativas a feixes de retas paralelas 
cortadas por retas secantes ou do teorema de Pitágoras (BRASIL, 2018, p. 272).

Dentre os conteúdos abordados no ensino da geometria espacial, os corpos regulares, também chamados de poliedros regulares, vem sendo tratados por diversos autores ao longo da história, dentre eles o frade italiano, Luca Pacioli (1447-1517). Em seu tratado De Divina Proportione, escrito em 1498 como presente para o, então, duque de Milão, Ludovico Sforza (1452-1508), e publicado em 1509, o autor versa sobre a divina proporção, suas consequências e algumas aplicações.

Em meio ao texto da obra, seu capítulo XXV traz à tona uma característica pouco usual no ensino do conceito de corpos regulares: o emprego dos ângulos sólidos e ângulos superficiais. Tal conhecimento é apresentado, também, na obra de Euclides, Os Elementos, a qual serve como base para se compreender os escritos de Luca Pacioli.

\title{
Caminho metodológico
}

Esse estudo se caracteriza como uma pesquisa de cunho qualitativo, que, segundo Prodanov e Freitas (2013, p. 70),

\begin{abstract}
[...] considera que há uma relação dinâmica entre o mundo real e o sujeito, isto é, um vínculo indissociável entre o mundo objetivo e a subjetividade do sujeito que não pode ser traduzido em números. A interpretação dos fenômenos e a atribuição de significados são básicas no processo de pesquisa qualitativa. Esta não requer o uso de métodos e técnicas estatísticas. O ambiente natural é a fonte direta para coleta de dados e o pesquisador é o instrumento-chave. Tal pesquisa é descritiva. Os pesquisadores tendem a analisar seus dados indutivamente. $\mathrm{O}$ processo e seu significado são os focos principais de abordagem.
\end{abstract}

Também, segue o viés de uma investigação bibliográfica, isto é, "quando elaborada a partir de material já publicado, [...]com o objetivo de colocar o pesquisador em contato direto com todo material já escrito sobre o assunto da pesquisa" (PRODANOV; FREITAS, 2013, p. 54), bem como de uma investigação documental, ou seja, aquela que "baseia-se em materiais que não receberam ainda um tratamento analítico ou que podem ser reelaborados de acordo com os objetivos da pesquisa" (PRODANOV; FREITAS, 2013, p. 55).

Em relação aos procedimentos de verificação, buscou-se em sete dos oito livros didáticos aprovados no Plano Nacional do Livro Didático (PNLD) para o triênio 20182020 de que forma está proposta a definição de corpos regulares nessas obras. Além disso, 
O conceito de corpos regulares em alguns livros didáticos e sua relação com o tratado De Divina

verificou-se de que forma a história da matemática é abordada no ensino dessa temática em cada livro. O quadro 1 a seguir lista os títulos consultados.

Quadro 1 - Livros do PNLD 2018-2020 analisados

\begin{tabular}{|c|c|c|c|c|}
\hline CÓDIGO & AUTORES & TÍTULO & EDITORA & ANO \\
\hline LD1 & Luiz Roberto Dante & $\begin{array}{l}\text { Matemática - Contexto } \\
\& \text { Aplicações }\left(2^{\circ} \text { ano }\right)\end{array}$ & Ática & 2016 \\
\hline LD2 & $\begin{array}{c}\text { Eduardo Chavante e } \\
\text { Diego Prestes }\end{array}$ & $\begin{array}{c}\text { Quadrante - } \\
\left.\text { Matemática ( } 3^{\circ} \text { ano }\right)\end{array}$ & SM & 2016 \\
\hline LD3 & $\begin{array}{c}\text { Gelson Iezzi, Osvaldo } \\
\text { Dolce, David } \\
\text { Degenszajn, Roberto } \\
\text { Périgo e Nilze de } \\
\text { Almeida } \\
\end{array}$ & $\begin{array}{c}\text { Matemática: Ciências e } \\
\text { Aplicações }\left(2^{\circ} \text { ano }\right)\end{array}$ & Saraiva & 2016 \\
\hline LD4 & Rodrigo Balestri & $\begin{array}{l}\text { Matemática: Interação } \\
\left.\text { e Tecnologia ( } 3^{\circ} \text { ano }\right)\end{array}$ & Leya & 2016 \\
\hline LD5 & $\begin{array}{c}\text { Joamir Souza e } \\
\text { Jacqueline Garcia }\end{array}$ & $\begin{array}{c}\text { \#Contato Matemática } \\
\left(2^{\circ} \text { ano }\right)\end{array}$ & FTD & 2016 \\
\hline LD6 & Manoel Paiva & $\begin{array}{c}\text { Matemática - Paiva }\left(2^{\circ}\right. \\
\text { ano) }\end{array}$ & Moderna & 2015 \\
\hline LD7 & $\begin{array}{l}\text { Fabio Martins de } \\
\text { Leonardo }\end{array}$ & $\begin{array}{c}\text { Conexões com a } \\
\text { Matemática }\left(2^{\circ} \text { ano }\right)\end{array}$ & Moderna & 2016 \\
\hline
\end{tabular}

Fonte: Elaborado pelo autor (2019)

Para o estudo, foram elencados os seguintes critérios: (1) Apresentação do conceito de corpos regulares na obra; (2) Demonstração da existência de apenas cinco corpos regulares; (3) Presença da história da matemática sobre o conteúdo estudado; (4) Relação com o conceito presente em De Divina Proportione.

A opção por esse material se deu essencialmente por serem os livros disponibilizados pelo Ministério da Educação para a rede pública de ensino. No entanto, devido a impossibilidade de acesso, um dos oito livros aprovados não pôde ser consultado, sendo omitido no quadro 1.

Em relação ao tratado De Divina Proportione, utilizou-se como referência a versão de Bertato (2010) para a obra de Luca Pacioli, que consiste na tradução da obra original para o português brasileiro através do cotejamento entre a versão manuscrita, de 1498, e a versão impressa, de 1509. 


\section{$O$ conceito de corpos regulares em alguns livros didáticos}

Os livros didáticos fazem parte do cotidiano da educação básica da rede pública brasileira, sendo utilizados como suporte às aulas das disciplinas lecionadas nas escolas. No que concerne à sua escolha, o processo se inicia pela seleção do Ministério da Educação, chegando às mãos dos professores para que decidam qual das obras mais se adequa ao seu plano e à proposta pedagógica da instituição de ensino.

A partir de uma leitura minuciosa dos títulos indicados no quadro 1, foi realizada uma varredura dos quatro critérios previamente escolhidos, a fim de fazer uma descrição de como o conceito de corpos regulares está presente nessas obras. A seguir, são apresentados os dados resultantes dessa verificação em relação ao conceito estudado.

\section{LD1: Matemática - Contexto \& Aplicações}

Em LD1, o conteúdo que versa sobre os corpos regulares encontra-se no oitavo capítulo do volume 2 da coleção, pertinente ao segundo ano do ensino médio. Antecedendo o conceito de poliedros regulares, são apresentados o conceito geral de poliedro, a distinção entre poliedros convexos e não convexos e a relação de Euler.

Para o autor, "um poliedro convexo é regular quando todas as faces são polígonos regulares e congruentes e em todos os vértices concorre o mesmo número de arestas" (DANTE, 2016, p. 172). Seguida dessa definição, encontra-se a demonstração da existência de apenas cinco poliedros regularas através de manipulações algébricas da relação de Euler: $v-a+f=2$, onde $v, a$ e $f$ são, respectivamente, os números de vértices, arestas e faces do poliedro.

Em momento algum há a presença de elementos que remetam à história da matemática, exceto pelo fato de que são apresentados os anos de nascimento e morte de Leonard Euler. Além disso, não há qualquer contextualização com o conteúdo estudado.

\section{LD2: Quadrante - Matemática}

Em LD2, o conteúdo que versa sobre os corpos regulares encontra-se no segundo capítulo do volume 3 da coleção, referente ao terceiro ano do ensino médio. Assim como em LD1, esta obra apresenta o conceito de poliedro, a distinção entre poliedros convexos e não convexos e a relação de Euler. 
Para os autores, um poliedro convexo é definido como regular "quando todas as suas faces são polígonos regulares iguais e em todos os vértices concorrem a mesma quantidade de arestas" (CHAVANTE; PRESTES, 2016, p. 42). Além disso, LD2 também traz uma demonstração da existência de apenas cinco corpos regulares através de manipulações algébricas da relação de Euler.

Em relação à abordagem histórica, Chavante e Prestes (2016) recorrem à obra de Howard Eves, Introdução à história da matemática, como fonte, mas se limitam a apresentar informações biográficas a respeito de Euler e Platão, sobre o qual o que há de relevante é a utilização de triângulos para a formação das faces dos corpos regulares, conforme apresentado em sua obra, Timeu.

\section{LD3: Matemática: Ciências e Aplicações}

Em LD3, o conteúdo que versa sobre os corpos regulares encontra-se no oitavo capítulo do volume 2 da coleção, destinado ao segundo ano do ensino médio. Nesta obra, os corpos regulares são apresentados apenas no final do capítulo, em uma seção denominada "Complemento sobre poliedros", onde o conteúdo buscado é precedido pelo conceito de poliedros convexos e a relação de Euler.

Em LD3, os poliedros regulares são conceituados conforme se segue:

Um poliedro convexo é regular se:

- $\quad$ suas faces são polígonos regulares e congruentes.

- $\quad$ em cada vértice concorre o mesmo número de arestas, pois as faces são congruentes.

No poliedro regular é possível notar que:

- todas as faces têm o mesmo número de arestas, pois as faces são congruentes.

- todos os vértices são pontos de interseção de um mesmo número de arestas.

- $\quad$ ele satisfaz a relação de Euler, pois é convexo.

Desse modo, todo poliedro regular é poliedro de Platão.

Existem, dessa forma, cinco tipos de poliedros regulares, representados ao lado (IEZZI et al., 2016, p. 190).

Ao lado do texto citado anteriormente, são apresentadas as imagens dos cinco corpos regulares: tetraedro, hexaedro, octaedro, dodecaedro e icosaedro regulares. Esta é toda informação que há em LD3 sobre o tema buscado. Não há demonstrações sobre a existência dos cinco corpos regulares nesta seção, pois elas são apresentadas ao longo do capítulo 8 da obra, quando Iezzi et al. (2016) trata dos poliedros de Platão. 
No que se refere à aspectos históricos, não há nada relacionado diretamente aos corpos regulares e, ao longo do capítulo 8 da obra, há apenas uma contextualização com obras arquitetônicas de vários países, inclusive sobre as pirâmides do Egito.

\section{LD4: Matemática - Interação e Tecnologia}

Em LD4, o conteúdo que versa sobre os corpos regulares encontra-se no segundo capítulo do volume 3 da coleção, pertencente ao terceiro ano do ensino médio. Nesta obra, o conceito de corpos regulares é precedido pela noção de poliedro, pela distinção entre poliedros convexos e não convexos, pela relação de Euler e pela definição de poliedros de Platão.

Para o autor, "um poliedro convexo é chamado de poliedro regular quando satisfaz as seguintes condições: Todas as faces são polígonos regulares e congruentes entre si. De cada vértice partem o mesmo número de arestas" (BALESTRI, 2016, p. 43). Quanto à demonstração da existência dos cinco corpos regulares, LD4 apresenta uma através de uma comparação com a definição de poliedros de Platão, seguida das planificações destes corpos.

Em relação ao conteúdo histórico, Balestri (2016) apresenta um curto texto intitulado "Mística dos poliedros", decorrente de um excerto da obra de Carl Boyer, História da Matemática, o qual cita a relação de cada corpo regular com um elemento da natureza e, também, o universo. Além disso, constam curtas informações biográficas a respeito de Euler e Platão.

\section{LD5: \#Contato Matemática}

Em LD5, o conteúdo que versa sobre os corpos regulares encontra-se no oitavo capítulo do volume 2 da coleção, relativo ao segundo ano do ensino médio. Essa obra traz o conceito de corpos regulares após apresentar a noção de poliedro, a distinção entre poliedros convexos e não convexos, a relação de Euler e a definição de poliedros de Platão.

Segundo se apresenta em LD5, Souza e Garcia (2016, p. 208) citam que "um poliedro convexo é regular quando satisfaz as seguintes condições: as faces são polígono regulares e congruentes entre si; de cada vértice do poliedro parte o mesmo número de arestas”. E, em sua continuação, demonstram a existência de apenas cinco corpos 
regulares mencionando que "Se um poliedro é regular, suas faces são polígonos regulares e congruentes entre si e, desse modo, todas as faces têm o mesmo número de lados. Além disso, em um poliedro regular, de cada vértice parte o mesmo número de arestas" (SOUZA; GARCIA, 2016, p. 208). O que, segundo os autores, garante que todo poliedro regular é poliedro de Platão.

No que se refere à abordagem histórica, em LD5 encontram-se informações biográficas sobre a vida de Euler e de Platão, sobre o qual é mencionada a associação dos corpos regulares aos elementos da natureza. Além disso, Souza e Garcia (2016) utilizaram como fontes de pesquisa as obras de Carl Boyer e Howard Eves, anteriormente citadas.

\section{LD6: Matemática - Paiva}

Em LD6, o conteúdo que versa sobre os corpos regulares encontra-se no oitavo capítulo do volume 2 da coleção, pertinente ao segundo ano do ensino médio. Nesta obra, o conceito de corpos regulares é precedido por noções básicas e essenciais à compreensão da geometria espacial, como posições relativas entre pontos, retas e planos, perpendicularidade e ângulos no espaço, bem como a definição de poliedro, a distinção entre poliedros convexos e não-convexos e a relação de Euler.

Segundo o autor,

Um poliedro convexo é regular se, e somente se, são satisfeitas as seguintes condições:

I. todas as suas faces são polígonos regulares e congruentes entre si;

II. todos os ângulos poliédricos são regulares e congruentes entre si.

Intuitivamente, dois ângulos poliédricos são congruentes se é possível "encaixar" um no outro, de modo que o vértice e as arestas deles coincidam, respectivamente, com os vértices e as arestas do outro (PAIVA, 2015, p. 192).

Em uma visão geral, a definição presente em LD6 tem como característica marcante o emprego dos ângulos poliédricos e não faz menção à relação de Euler. Assim, nota-se que é possível definir os corpos regulares por outros meios. Além disso, são apresentados posteriormente no referido capítulo os cinco corpos regulares, mas não há qualquer demonstração da garantia de sua existência.

No que concerne à contextualização histórica, LD6 se restringe a apresentar notas biográficas sobre Leonard Euler. E apesar da definição enunciada por Paiva (2015) seguir uma característica diferente, não há nada referente à sua história. 


\section{LD7: Conexões com a Matemática}

Em LD7, o conteúdo que versa sobre os corpos regulares encontra-se no sexto capítulo do volume 2 da coleção, destinado ao segundo ano do ensino médio. No referido capítulo, encontram-se conceitos referentes aos sólidos geométricos em geral, aos prismas e às pirâmides. Além disso, também contém a noção de poliedro, a distinção entre poliedros convexos e não convexos e a relação de Euler.

Para o autor, "Um poliedro convexo é regular quando satisfaz às seguintes condições: apresenta todas as faces poligonais regulares e congruentes entre si; em todos os vértices concorre o mesmo número de arestas" (LEONARDO, 2016, p. 107). Em LD7, não há demonstração da existência de apenas cinco corpos regulares, mas apenas sua representação em figuras.

No que se refere a conteúdos históricos, LD7 se limita a apresentar informações biográficas sobre Leonard Euler. Não há menção a fatos diretamente ligados aos corpos regulares ou sobre outros matemáticos que tenham os estudado.

\section{Relacionando os resultados obtidos com o tratado De Divina Proportione}

$\mathrm{Na}$ descrição apresentada anteriormente, seis dos sete livros didáticos de matemática selecionados para o estudo apresentam definições sobre corpos regulares atrelado a relação de Euler. Entretanto, o livro LD6 (PAIVA, 2015) apresenta uma definição através dos ângulos poliédricos.

Essa definição se assemelha com a apresentada por Luca Pacioli no capítulo XVI de seu tratado, De Divina Proportione e segue a mesma ideia, a qual é abordada também por Euclides em Os Elementos. Para uma melhor compreensão do conceito de corpos regulares segundo Pacioli (2010), seguem as definições de Euclides (2009) para ângulo superficial e ângulo sólido encontradas em Os Elementos, obra indicada pelo próprio frade como "guia indispensável” (BERTATO, 2010).

No livro I de Os Elementos, a oitava definição se refere ao ângulo superficial, chamado de ângulo plano, enunciando-o como “[...] a inclinação, entre elas, de duas linhas no plano, que se tocam e não estão postas sobre uma reta" (EUCLIDES, 2009, p. 97). Em relação ao caso dos corpos regulares, entende-se que o ângulo superficial é cada ângulo interno das faces do corpo. 
Já a décima primeira definição do livro XI da mesma obra se refere a ângulo sólido como:

[...] a inclinação por mais de duas retas que se tocam e que não estão na mesma superfície, relativamente a todas as retas. De outro modo: o ângulo sólido é o contido por mais de dois ângulos planos, que não estão no mesmo plano, construídos em um ponto (EUCLIDES, 2009, p. 482).

Assim, também numa situação que envolve os corpos regulares, entende-se que o ângulo sólido se trata do concurso dos ângulos superficiais em um mesmo vértice, isto é, o ângulo poliédrico.

Segundo Pacioli (2010, p. 28), os corpos regulares são definidos como "aqueles cujas bases são iguais entre si e de ângulos sólidos e planos iguais e, similarmente, de lados iguais". Percebe-se, então, que há uma relação com as bases e os lados dos referidos corpos. Em termos da matemática atual, entende-se que as bases são o que conhecemos como as faces do corpo regular e os lados, suas arestas. Nota-se que a definição de Pacioli (2010) não se refere à relação de Euler, pois, dentre diversas razões, a publicação do tratado De Divina Proportione data do século XVI, enquanto os registros de Euler datam do século XVIII.

Percebe-se, então, que Paiva (2015), apesar de não fazer qualquer menção ao frade italiano Luca Pacioli, apresenta em LD6 uma definição bastante semelhante à citada em De Divina Proportione, exceto pelo fato de não se referir ao emprego dos ângulos superficiais. Ainda assim, a definição apresentada em LD6 mostra um outro caminho que pode ser seguido para se compreender os corpos regulares.

\section{Considerações finais}

O presente estudo buscou conhecer o conceito corpos regulares em livros didáticos de matemática aprovados no PNLD para o triênio 2018-2020. Tendo em vista o cenário no qual eles estão inseridos, percebe-se que há um enfoque do conteúdo na relação de Euler. Entretanto, em um dos livros didáticos consultados, observa-se uma aproximação conceitual com o que é apresentado no tratado do século XVI, De Divina Proportione. No quadro 2, consegue-se visualizar, de uma forma panorâmica o resultado do estudo. 
Quadro 2 - Síntese do estudo.

\begin{tabular}{|l|l|l|l|l|l|l|l|}
\hline \multicolumn{1}{|c|}{ CRITÉRIOS } & LD1 & LD2 & LD3 & LD4 & LD5 & LD6 & LD7 \\
\hline $\begin{array}{l}\text { Apresentação do conceito de corpos } \\
\text { regulares }\end{array}$ & & & & & & & \\
\hline $\begin{array}{l}\text { Demonstração da existência de } \\
\text { apenas cinco corpos regulares }\end{array}$ & & & & & & & \\
\hline $\begin{array}{l}\text { Presença da história da matemática } \\
\text { sobre o conteúdo analisado }\end{array}$ & & & & & & & \\
\hline $\begin{array}{l}\text { Relação com o conceito presente em } \\
\text { De Divina Proportione }\end{array}$ & & & & & & & \\
\hline
\end{tabular}

Fonte: Elaborado pelo autor (2019).

Visando também a inserção da história ao ensino de matemática, na descrição de aspectos correlatos a isso, nota-se que os livros didáticos indicados utilizam-se de escassas informações históricas sobre o conceito de corpos regulares, as quais, na sua maioria, se resumem a dados biográficos sobre Leonard Euler e Platão. Tal escassez já vem sendo relatada em estudos que visavam identificar como se dá a presença da história da matemática em livros didáticos (ALENCAR, 2018; OLIVEIRA; SOUSA, 2018).

Vale ressaltar que esse estudo não visa julgar qual das definições apresentada nos livros indicados para a educação pública é mais didática, mas sim conhecer como estas são propostas, articulando com os conceitos encontrados em De Divina Proportione. Entretanto, percebeu-se que contextos históricos referentes à geometria espacial, em particular sobre os corpos regulares, pouco têm sido abordados.

Na intenção de colaborar na redução dessa ausência, um estudo acerca dos corpos regulares abordados por Luca Pacioli em seu tratado está sendo desenvolvido, levando em consideração não só os aspectos matemáticos concernentes a essa temática, mas também o contexto histórico pertinente através de uma visão historiográfica atualizada. Dessa forma, espera-se contribuir na formação de professores de matemática e, consequentemente, de seus alunos, estreitando as relações entre a história e o ensino de matemática.

\section{Referências}

ALENCAR, Alexsandro Coelho. Uma análise discursiva sobre a História da Matemática presente no livro didático de Matemática. Boletim Cearense de Educação e História da Matemática, Fortaleza, v. 5, n. 14, p.299-310, 27 ago. 2018. Número Especial - III Seminário Cearense de História da Matemática. Disponível em: 
O conceito de corpos regulares em alguns livros didáticos e sua relação com o tratado De Divina Proportione (1509)

Alison Sousa da Silva

https://revistas.uece.br/index.php/BOCEHM/article/view/248/193. Acesso em: 20 dez. 2019.

BALESTRI, Rodrigo. Matemática: interação e tecnologia. 2. ed. São Paulo: Leya, 2016. $3 \mathrm{v}$.

BERTATO, Fabio Maia. A "De Divina Proportione" de Luca Pacioli: tradução anotada e comentada. Campinas: UNICAMP, 2010. 56 v. Coleção CLE.

BRASIL. Ministério da Educação. Base Nacional Comum Curricular: Educação é a base. Brasília: MEC, 2018.

BRASIL. Secretaria de Educação Fundamental. Parâmetros Curriculares Nacionais: Matemática. Brasília: MEC, 1998.

CHAVANTE, Eduardo; PRESTES, Diego. Quadrante matemática. São Paulo: SM, 2016. $3 \mathrm{v}$.

DANTE, Luiz Roberto. Matemática: contexto e aplicações. 3. ed. São Paulo: Ática, 2016. $3 \mathrm{v}$.

EUCLIDES. Os Elementos. São Paulo: UNESP, 2009. Tradução e introdução de Irineu Bicudo.

IEZZI, Gelson et al. Matemática: ciência e aplicações. 9. ed. São Paulo: Saraiva, 2016. $3 \mathrm{v}$.

LEONARDO, Fábio Martins de (ed.). Conexões com a matemática. 3. ed. São Paulo: Moderna, 2016. $3 \mathrm{v}$.

OLIVEIRA, Francisco Wagner Soares; SOUSA, Ana Cláudia Gouveia de. O Livro didático e a história no ensino de matemática: limitações e possibilidades. Boletim Cearense de Educação e História da Matemática, Fortaleza, v. 5, n. 13, p.16-27, 01 jun. 2018. Disponível em:

https://revistas.uece.br/index.php/BOCEHM/article/view/21/36. Acesso em: 20 dez. 2019.

PAIVA, Manoel. Matemática: Paiva. 3. ed. São Paulo: Moderna, 2015. 3 v.

PRODANOV, Cleber Cristiano; FREITAS, Ernani Cesar de. Metodologia do trabalho científico: métodos e técnicas da pesquisa e do trabalho acadêmico. 2. ed. Novo Hamburgo: Feevale, 2013.

SOUZA, Joamir; GARCIA, Jacqueline. \#Contato matemática. São Paulo: FTD, 2016. $3 \mathrm{v}$. 